\title{
Is policy the problem or the solution for Indigenous people? A Rejoinder to Gary Johns
}

\section{Boyd Hunter ${ }^{1}$}

In my paper entitled 'Conspicuous Compassion and Wicked Problems: The Howard Government's National Emergency in Indigenous Affairs' (Hunter 2007a) in a recent issue of Agenda, the reference to 'wicked problems' was an attempt to extend the debate over 'the intervention' by drawing on the theorising in public policy about appropriate responses to complex, multi-dimensional problems; problems which are intrinsically hard to define because multiple stakeholders have differing perspectives on what the underlying problem is: 'wicked problems' (see also Commonwealth of Australia 2007).

In the last issue of Agenda Gary Johns (2008) asked whether the underlying cause of Indigenous disadvantage in the Northern Territory is a 'wicked problem' or the result of 'wicked policy' of 'self-determination'. Johns argues that Indigenous disadvantage can only be solved by changing the system of government support and infrastructure so that people face the true costs of their decision to stay in remote communities - that is, to encourage mobility to more buoyant labour markets where jobs are available. More generally, Johns argues for a policy of 'economic integration', on the grounds that the modernisation project is (necessarily) inconsistent with cultural maintenance.

One problem with Johns' argument is that it ignores some of the difficulties that Indigenous workers have in securing jobs in urban labour markets. One important constraint in this regard may be the existence of ongoing labour-market discrimination (Hunter 2005). Another issue is the mismatch between the skills demanded by employers and the skill set that Indigenous people currently have.

Further, while I allow - and raised in my paper - the prospect that there is some partial inconsistency, or trade-off, between modernisation and cultural maintenance, I believe that the extent of such a trade-off is an empirical question. Granted, it is possible to argue that maintaining a cultural identity that is distinct from the mainstream Australian norms might foreclose some employment and education options. However, the evidence seems to indicate that such fears can be overstated. For example, Hunter (2007b) shows that youth who speak an Indigenous language are actually more likely to attend school.

\footnotetext{
${ }^{1}$ Centre for Aboriginal Economic Policy Research, The Australian National University, Boyd.Hunter@anu.edu.au
} 
The policy 'take-away' of Johns' paper is a radical change in the set of incentives for mobility facing Indigenous people: the removal of unconditional income support and services provided in such communities by Community Development Employment Projects (CDEP) schemes or other government initiatives. The optimal level of mobility depends on both the individual and the social costs and benefits of moving. Even if one is willing to ignore Indigenous perspectives on culture and interventions made on their behalf, it is not entirely clear to me that mobility will necessarily result in the benefits anticipated by Johns - especially when one takes into account the likelihood that there will be substantial short-run adjustment costs (for example, in social dislocation) and the difficulty that many Indigenous people have in securing employment in complex labour markets.

Another factor that is discounted in Johns' analysis is that the ongoing existence of an authentic and living Indigenous culture has a considerable market and non-market value to both Indigenous and non-Indigenous Australians. From a national perspective, CDEP jobs are also important for much of the natural-resource management work undertaken in remote Australia. For example, Indigenous Protected Areas are an integral part of the conservation estate, and ensuring that such areas are adequately maintained is in the national interest.

One aspect of Johns' argument that I do agree with is that the CDEP scheme supports the existence of remote Indigenous communities that might not continue to exist if all government support were withdrawn. In that sense, the CDEP scheme provides tangible support to Indigenous culture in such areas. Furthermore, as I argue elsewhere (Hunter 2008), mainstream (non-CDEP) jobs provide more protection against entrenched Indigenous disadvantage than CDEP scheme jobs. Consequently, one can argue that there is, in a sense, a trade-off between cultural maintenance (which is clearly supported by the CDEP scheme) and other important socioeconomic dimensions of Indigenous social exclusion.

Hence, whatever one's positions on the validity of the arguments put forward in our respective papers, I believe public debate would be enhanced by the further evaluation of the extent of trade-off between cultural maintenance and integration into the mainstream economy. The main impediment for this research agenda is that 'culture' is a difficult, if not impossible, concept to define and measure - notwithstanding that this trade-off is a central issue which continues to divide the respective protagonists in this debate.

From my perspective, one of the major weaknesses with the intervention was that it did not incorporate a transparent evaluation framework. Hence there is no way to adequately evaluate the outcomes or attribute them to this or any other policy initiatives. The lack of an adequate pre-existing benchmark is even more evident for evaluating the policy of 'self-determination', as the quality of Indigenous data was even more dubious in the early 1970s. No major change in 
policy would be enacted in the United States without putting in place a strategy for evaluating the outcomes - many US policy initiatives even incorporate social experiments (with random assignment) into their original design. It is time that Australia considered doing the same.

In summary, my main criticism of Johns (2008) is that he ignores the aspects of Indigenous disadvantage that make it a wicked problem. Policy cannot be drawn up without proper consultation with the people affected by the policy. The fact that some of the people targeted by the NT intervention have a different perspective from that of policymakers is likely to increase their resistance to the implementation of that policy. However, if policy is not designed to take into account, or is otherwise adapted to, the current behaviour and preferences of the target population, then it should be acknowledged that such policies may perpetuate the underlying problems. That is, policy can simultaneously be both part of the problem and part of the solution.

\section{References}

Commonwealth of Australia 2007, 'Tackling Wicked Problems: A Public Policy Perspective', Australian Public Service Commission, Canberra.

Hunter, B. H. 2005, 'The role of discrimination and the exclusion of Indigenous people from the labour market' in D. Austin-Broos and G. Macdonald (eds), Culture, Economy and Governance in Aboriginal Australia, University of Sydney Press, Sydney.

Hunter, B. H. 2007a, 'Conspicuous Compassion and Wicked Problems: The Howard Government's National Emergency in Indigenous Affairs', Agenda 14(3): 35-54.

Hunter, B. H. 2007b, 'Cumulative Causation and the Productivity Commission's Framework for Overcoming Indigenous Disadvantage', Australian Journal of Labour Economics 10(3): 185-202.

Hunter, B. H. 2008, 'A half hearted defence of CDEP scheme', a seminar presented in the CAEPR series on 12 March 2008; available at: http://www.anu.edu.au/caepr

Johns, G. 2008, 'The Northern Territory Intervention in Aboriginal Affairs: Wicked Problem or Wicked Policy?', Agenda 14(3): 65-84. 